\title{
Network Reactions to Banking Regulations ${ }^{\text {th }}$
}

\author{
Selman Erol ${ }^{1}$ \\ Massachusetts Institute of Technology and Carnegie-Mellon University \\ Guillermo Ordoñez ${ }^{2}$ \\ University of Pennsylvania and NBER
}

\begin{abstract}
Optimal regulatory restrictions on banks have to solve a delicate balance. Tighter regulations reduce the likelihood of banks' distress. Looser regulations foster the allocation of funds towards productive investments. With multiple banks, optimal regulation becomes even more challenging. Banks form partnerships in the interbank lending market to face liquidity needs and meet investment possibilities. We show that the interbank network may suddenly collapse once regulations are pushed above a critical level, with a discontinuous increase in systemic risk as banks' cross-insurance collapses.
\end{abstract}

Keywords: banking regulations, interbank networks, systemic risk.

\section{Introduction}

Banks provide a key intermediation function in the economy. They extend loans to agents with productive investment opportunities using funds from depositors without access to those opportunities. As banks' investments may fail, 5 depositors are only willing to provide the funds if ex-ante compensated for potential losses, which forces bankers to internalize failure and to invest efficiently, both in terms of scale and risk exposure. The scenario changes, however, in the presence of governments with ex-post incentives to cover the losses of depositors with distortionary taxation proceedings. These bailouts provide an implicit insurance for depositors that allow banks to obtain funds at a subsidized rate, then investing excessively, either at a larger scale or taking more risks, relative to the efficient allocation. As highlighted by Nosal and Ordonez (2016), when

\footnotetext{
Whe especially thank Marvin Goodfriend, Burton Hollifield and Maryam Farboodi for excellent suggestions to improve the paper. We also thank Douglas Diamond, Narayana Kocherlakota, Jonathan Parker, Rakesh Vohra and the participants at the Carnegie-RochesterNYU Conference in Pittsburgh for comments. The usual waiver of responsibilities applies.

${ }^{1}$ Email: erols@mit.edu, Address: 50 Memorial Drive, Cambridge MA, 02142.

2Email: ordonez@econ.upenn.edu, Address: 3718 Locust Walk, 428 McNeil Building, Philadelphia, PA 19104.
} 
the government lacks commitment not to bail out depositors in distress, banks tend to invest excessively and inefficiently, increasing the likelihood and the magnitude of crises and the need for distortionary bailouts.

In response to this time inconsistency the government tends to regulate banking activity, in part to counteract these perverse ex-ante banks' incentives. The banking regulations that are introduced to restrict the volume of investments take several forms. Capital requirements specify the level of equity that

20 a bank must hold as a percentage of its risk-weighted assets. Liquidity and reserve requirements impose a direct upper bound on the amount of loans that can be extended by a bank per U.S. dollar kept physically in possession of the bank. Credit rating requirements curb the choice of projects that a bank can choose to maintain a certain credit qualification. Financial disclosure require25 ments increase the cost of extending and managing loans. Even though all these restrictions are introduced to assess different risks, all have the consequence of restricting the volume of banks' assets.

Too tight regulations reduce excessive investments and risk-taking and then the needs for bailouts, but may end up choking the banks' role to channel funds

30 to productive investment opportunities. When these two forces change smoothly on the level of regulatory requirements for an individual bank, it should be in principle possible to obtain the optimal level of regulation that counteracts the banks' incentives to extend excessive (and excessively risky) loans.

Even though this logic is sound when considering a single bank, it becomes 35 more challenging when considering multiple banks that interact with each other. Indeed, banks do not operate in isolation and react liquidity needs by making loans to each other, in the overnight interbank lending market, at relatively low rates. After extending loans for a lucrative investment opportunity, a bank may fall short of the liquidity needed to cover both the liquidity requirements and 40 potential extra refinancing needs to continue old projects or to take advantage of new profitable new projects, referring to other banks for short-term loans in order to satisfy these needs. This implies that the tightness of regulatory constraints may have a first-order impact on the vibrancy and interconnectedness of the interbank market. How does the interbank network react to changes in 45 regulation? How should regulation be determined in a setting with interacting banks? How does the endogenous formation of interbank networks affect the welfare effects of regulation?

In this paper we explore these questions and show that the topology and the level of interconnectedness of the interbank network react discontinuously 50 to regulatory requirements, adding an additional layer of complexity to the delicate balance that optimal banking regulations should strive to achieve. The reaction of an interbank network features a "phase transition": beyond a tipping point of regulatory requirements, the network becomes disproportionately less interconnected, with systemic risk increasing discontinuously in response to this 55 abrupt change in the network architecture.

To fix ideas we will focus on a specific type of regulatory constraints: liquidity requirements. On the one hand, the coverage of liquidity shortages is one of the main functions of interbank lending, constituting the blood of banking networks 
operations. On the other hand, a microfounded model encompassing regulation in general would require many more elements than those needed to show the deep source of network fragility: restrictions on the volume of loans. Even though we craft our model to capture specifically restrictions on the ratio of liquid to illiquid assets, we map our results to other banking regulations and show we should expect the same fragility from them.

${ }_{65}$ In our model, the benefit of having an interbank counterparty is to have additional "insurance" in case of a refinancing shock that requires extra funds to continue or expand some of a bank's investments. Even though some of the bank's counterparties is expected to become insolvent, the rest can provide extra liquidity in case of a refinancing shock. On the one hand, the marginal benefit of 70 having an extra counterparty decreases as liquidity requirements tighten up, as the loan sizes decline and banks obtain less benefits from insuring continuation of those projects. On the other hand, we assume the marginal cost of an extra counterparty is independent of the liquidity requirement or the investment scale.

As liquidity requirements tighten, we do not only show that the desired level

75 of counterparties decreases, but also that, after a critical point, a bank would discontinuously prefer to reduce its counterparties, with the network structure changing suddenly from very dense to very sparse and the aggregate level of interbank activity collapsing. In other words, as liquidity requirements tighten, not only the level of investment declines but also systemic risk, measured by

so the fraction of banks that choose to close operations, increases (discontinuously after a certain threshold). These sudden changes induce a discontinuous increase in distortionary bailouts and a discontinuous decline in welfare.

The logic behind the fragility of the network structure relies on the strategic considerations of a bank when choosing its level of connectivity. When a bank 85 chooses how many counterparties to have, it takes into account how many of those counterparties will, in expectation, be able to provide assistance in case of a refinancing need. How many of a bank's counterpaties will be able to provide assistance, however, depends on the number of counterparties that each of the bank's counterparty chooses to have. With many banks these strategic consid90 erations may be in principle intractable. Our model provides the conditions to have unique strongly stable network such that we can make comparative statics.

Creating a banking network model that put these strategic considerations at the forefront of the discussion is relevant for two reasons. First, these strategic considerations create a highly nonlinear response of the network to changes in ${ }_{95}$ regulation, as the connectivity decisions of other banks have a large impact on each bank's connectivity decisions. Second, a bank does not internalize the effects of its own connectivity decisions on others, creating severe externalities.

Our result also has important policy implications. We show that the highest welfare that takes into account endogenous network formation, and then takes 100 into account the network reaction to banking regulations, is achieved exactly at the tipping point after which networks discontinuously collapse. Just setting regulations at the tipping point that sustains dense networks assumes the absence of exogenous shocks to fundamentals. When fundamentals are subject to shocks, however, setting regulatory requirements at the tipping point 

fundamentals. This suggests that the optimal distance between regulatory requirements and the tipping point should balance the loss in welfare from being farther away from the tipping point and the gains from reducing the probability of the system moving beyond the tipping point, a crisis.

110 To assess the relevance of having into account the effect of banking regulations on networks we compare the liquidity requirements chosen by a networkconscious regulator, who understands the reaction of interbank insurance possibilities to changes in regulation, with those of a network-blind regulator, who does not understand that networks change with regulation. We show that the potential welfare losses from ignoring network reactions, in particular the discontinuous collapse, can be indeed large.

Literature Review: The recent financial crisis has been a catalyst for the interests both on banking regulations and on interbank networks. Even though there has been a recent rich literature on these two topics, our paper is one of the few, if not the first, to combine these two policy-relevant topics and analyze the effects of regulatory requirements on interbank network formation.

On regulatory constraints, most of the literature has focused on the optimal level of a single bank's liquidity requirement to prevent bank runs, such as Cooper and Ross (1998), Ennis and Keister (2006), Calomiris et al. (2014), Santos and Suarez (2015) and Diamond and Kashyap (2016). Using data on spreads, van den Heuvel (2016) recently computes the welfare costs of liquidity requirements and of capital requirements. He justifies the use of liquidity requirements by the existence of deposit insurance, which in principle can be changed directly by the government. In contrast, we justify liquidity requirements as a commitment device that ex-ante restrains the operations of banks because the government cannot commit not to bail them out ex-post.

In spite of these efforts, Allen (2014) surveys the recent literature on liquidity regulation, concluding that "much more research is required in this area. With capital regulation there is a huge literature but little agreement on the optimal 35 level of requirements. With liquidity regulation, we do not even know what to argue about." The confusion on the role of liquidity requirements to face liquidity shortages comes in large part from the lack of consensus of what a liquidity shortage is. While the referred previous literature focuses on using liquidity regulation to curb the effects of liquidity shocks on banks' short-term liabilities as in Diamond and Dybvig (1983), our paper focuses on using liquidity regulations to curb the effects of liquidity shocks on banks' assets refinancing needs as in Holmström and Tirole (1998).

A more recent literature focus on the effects of liquidity regulations when banking interconnections are acknowledged. Farhi et al. (2009), for example, 145 study the "externality" effects of regulation and the role of liquidity requirements to prevent free riding that occurs when the liquidity of one bank reduces the likelihood of a run in another bank. Aldasoro et al. (2015) construct a model of bank linkages and discuss the effects of banking regulations given the existence of banking interconnections. They show that liquidity requirements 
decreases systemic risks at the cost of lower efficiency. They study changes in regulation on risk and efficiency conditional on a network and not their effects on reshaping the network. This is an important difference, as we show that there exists a critical point beyond which liquidity requirements both increase systemic risks and reduce efficiency. To the best of our knowledge ours is the first paper to tackle the question of optimal regulation not only when there are externalities and interbank lending, but also when banks strategically react to regulation by changing the way they connect and insure each other.

On liquidity regulation, there is also a recent debate, sparked mostly by new regulatory proposals by the Basel Committee on Banking Supervision and ${ }_{160}$ by the Dodd Frank Act, about liquidity requirements that are alternative to standard reserve requirements, such as the liquidity coverage ratio (LCR) and the net stable funding ratio (NSFR). The LCR extends the interpretation of "liquid assets" beyond reserves, including assets with higher interest rates. The costs, complexity and discretion vulnerability of LCR relative to the potentially small benefits relative to the use of reserve requirements have been discussed by Goodfriend (2016). The NSFR defines the portion of capital and reliable liabilities that financial intermediaries have to maintain over a specified time horizon relative to the amount of required stable funding in that time period. Even though our setting is constructed to capture reserve requirements, it could 170 accommodate these two alternatives by including more assets classes (LCR) or a more involved timing of funding needs (NSFR).

Unfortunately there are not many empirical studies of the effects of policies on banking networks. An exception is Paddrik et al. (2016), who consistently with our model, show that the pattern of reserve requirements established by the National Banking Acts (NBA) in the U.S. dramatically changed the network structure of interbank deposits between 1862 and 1867 in Pennsylvania, reinforcing the linkages with Philadelphia and New York banks and weakening the linkages across county banks.

There is also a recent literature on endogenous networks, such as Erol and Vohra (2016), but not a systematic study to understand the endogenous reaction of financial networks to changes in banking regulations, and their effects on systemic risk and welfare. Allen and Gale (2000) discuss bankruptcy contagion in an exogenous network (modeled as a ring) and, consistent to our results, show a negative relation between the degree of connectivity and systemic risk. Battiston et al. (2012) show that the relation between connectivity and systemic risk can be hump shaped as low connectivity implies less risk-sharing and high connectivity implies more exposure to default of partners. Acemoglu et al. (2015) also show that the effects of connectivity can go in both directions. In a setting with heterogenous banks, Farboodi (2015) provides a model of banking networks that allow funds to flow from savers to investment opportunities, possibly over several links, and discusses the distribution of surplus depending on the network topology. None of these papers, however, have studied the change in networks induced by regulation and then optimal regulation taking networks into account.

195 Finally, while Ordonez $(2016)$ study the unforeseen effects of banking regula- 
tions on financial innovations that allow banks to channel activities outside the scope of regulators (the so-called "shadow banking"), in this paper we focus on the unforeseen effects of banking regulations on networks, through the creation and destruction of banking linkages, affecting both systemic risk and welfare. Understanding the unforeseen effects of banking regulations are important considerations to factor in the discussion about optimal regulations.

We structure the paper as follows. In the next section we present a simple model with liquidity requirements and the possibility of creating linkages with other banks to face possible refinancing needs. In Section 3 we explain the main forces in the model and show the characterization of the network structure for a given level of regulation. In Section 4 we study the effects of liquidity requirements on the anatomy of a banking network. In Section 5 we characterize optimal regulation by a network-conscious regulator that factors in network effects. In Section 6 we compute the welfare losses of a network-blind regulator who does not take the effects of regulations on networks into account. We conclude with some final remarks and considerations.

\section{Model}

\subsection{Environment}

We consider a single-period economy composed by $k$ risk-neutral banks, $k$ risk-neutral households and a government. We denote by $\mathcal{N}=\left\{n_{1}, \ldots, n_{k}\right\}$ the set of banks. Each bank $n_{i}$ has access to a unique project (of maximum possible scale, $\bar{L}_{i}$ ) to finance, and is associated with a unique household $n_{i}^{h}$. We assume that the household $n_{i}^{h}$ deposits $D_{i}$ in bank $n_{i}$ at the beginning of the period and wishes to withdraw and consume at the end of the period.

The timing of actions and events within the period can be split in five stages. The first stage is a regulation stage. The government sets a liquidity requirement $\phi \in[0,1]$, which imposes a minimum ratio of liquid to illiquid assets that a bank has to hold on its balance sheet. The role of the policy parameter $\phi$ is to restrict the bank's investments in risky and illiquid assets. At the end of the section we 225 will discuss how $\phi$ maps to policies that we observe in reality, such as reserve requirements, different types of liquidity requirements, capital requirements, etc.

The second stage is a network formation stage. Banks form links by mutual consent, that serve as credit lines to insure each other against future refinancing shocks that may put the maturity of the project at risk. A formed link between 230 banks $n_{i}$ and $n_{j}$ is denoted $l_{i j}=l_{j i}$, and the resulting set of links is denoted $\mathcal{L} \subset[\mathcal{N}]^{2}$. Then, $(\mathcal{N}, \mathcal{L})$ is the realized interbank network. Denote $\mathcal{N}_{i}=$ $\left\{j: l_{i j} \in \mathcal{L}\right\}$ the set of counterparties of $n_{i}$ and $d_{i}=\left|\mathcal{N}_{i}\right|$ its degree (the number of counterparties). Forming a link involves a utility cost $\kappa_{l}$ to each counterparty.

The third stage is an investment stage. Each bank $n_{i}$ extends in checks a loan of $L_{i}$ to finance the project, keeping its deposits $D_{i}$ as reserves. The liquidity requirement restricts the size of the loan (and then the scale of the project) to $L_{i}$, as $D_{i} \geq \phi L_{i}$, where $L_{i} \leq \bar{L}_{i}$ is the natural limit. Notice that when investing $L_{i}$ total assets are $D_{i}+L_{i}$ ( $D_{i}$ in cash and $L_{i}$ in loans) while total liabilities 
are also $D_{i}+L_{i}\left(D_{i}\right.$ as debt to the households, or "original depositors," and $L_{i}$ as debt to check holders, or "business depositors") ${ }^{3}$ The returns from the projects materialize at the end of the period. Banks' deposits and checks are also due at the end of the period.

The fourth stage is a continuation stage. The projects managed by all banks are publicly revealed to be $\theta_{i} \in\{B, G\}$, where $B$ represents a bad project that 245 never matures and $G$ a good project that can succeed if appropriate actions are taken by the bank in the next stage. These types are independent across banks, with $G$ happening with probability $\alpha_{i}$ and $B$ with probability $1-\alpha_{i}$.

After the projects' types are publicly observed, each bank $n_{i}$ chooses an action $a_{i}$. Banks managing good projects can choose to continue $(C)$ operating the project, or not $(N)$, then $a_{i} \in\{C, N\}$. Continuing operation has a management cost (an effort cost) of $\kappa_{c}$ per unit of investment and $\kappa_{l}^{\prime}$ to maintain the counterparty, making up a total of $\kappa_{c} L_{i}+\kappa_{l}^{\prime} d_{i}$. Banks with bad projects always choose $a_{i}=N$, as the bank would only pay the previous continuation costs, without recovering any payoffs form the project. Let $g_{i}$ and $f_{i}$ respectively denote the number of counterparties of $n_{i}$ that chose to continue and not continue: $g_{i}=\left|\left\{n_{j} \in \mathcal{N}_{i}: a_{j}=C\right\}\right|$ and $f_{i}=\left|\left\{n_{j} \in \mathcal{N}_{i}: a_{j}=N\right\}\right|$.

A bank $n_{i}$ with a good shock that chooses $N$ liquidates its project early and recovers $R_{1} L_{i}$ where $1>R_{1} \geq 0$. This implies that the total assets of a non-continuing bank at the end of the period are $D_{i}+R_{1} L_{i}$ while its total ${ }_{260}$ liabilities are $D_{i}+L_{i}$. We assume that the government faces a large (maybe political) disutility from depositors not obtaining their funds back at the end of the period. This simple assumption guarantees that the government would always bail out the defaulted depositors, for a total of $\left(1-R_{1}\right) L_{i}$. Banks $n_{i}$ that chooses not to continue then receive 0 .

A bank $n_{i}$ that chooses $C$, and continue business, moves to a fifth and last, refinancing stage. At that stage at most one of the projects of the continuing banks receives a refinancing shock, which is characterized by new funds that are needed in cash for the project to mature (a liquidity shock). The probability that a bank $n_{i}$, and only $n_{i}$, needs extra funds is $\eta_{i}$. With probability $\eta_{0}=1-\sum_{i} \eta_{i}$ 270 no project receives a refinancing shock. Conditional on the continuing bank $n_{i}$ receiving a refinancing shock, the amount of funds needed are $\rho_{i}$, drawn from a distribution with c.d.f. $F_{i}$. Investors can obtain these extra funds only from their associated counterparty banks in the network, not the others.

The banks not facing a refinancing shock and that have invested at scale $L_{i}$ obtain a return $R_{2} L_{i}$, where $R_{2}>1$. As for the bank facing the refinancing

\footnotetext{
${ }^{3}$ The project uses bank $n_{i}$ 's checks to operate, for example to buy raw materials or to pay workers. The recipients of these checks, for a total of $L_{i}$, eventually deposit them in the bank, becoming "business depositors." The assumption that a bank uses checks to finance its investment fully is an optimal bank's response when the project displays constant returns to scale and its return is higher than the return from holding cash. Under these circumstances the bank always chooses to lever as much as possible, with the amount of liquid assets given exogenously by $D_{i}$. Assuming an optimal portfolio choice is potentially interesting, but is not only beyond the scope of the paper but also complicates the network analysis considerably.
} 
need, if the bank obtains enough funds to refinance the liquidity need $\rho_{i}$, then the project's return scales by $m>\frac{1}{R_{2}}$ and pays an extra $\rho_{i}$, so that the return to $n_{i}$ is $m R_{2} L_{i}+\rho_{i}$. If the bank does not obtain enough funds to refinance the liquidity need, the project fails and returns 0 .

Finally, we assume that after the refinancing shock is observed, each household $n_{i}^{h}$ receives extra funds (say wages) for $W_{i}$, which are deposited at bank $n_{i}$ if $n_{i}$ has continued and is still in business. Then, without interbank activity, a bank $n_{i}$ facing a refinancing shock relies on its own available funds $W_{i}+D_{i}$ to ride the shock. This implies that in such case the bank would be able refinance the project to completion if and only if $\rho_{i} \leq W_{i}+D_{i}$.

Banks, however, may engage on interbank lending through credit lines (links) formed in advance at the network formation stage. We assume that funds do not travel further than one link as the main friction in the interbank market, that is a bank does not intermediate between two banks but rather intermediate between one household and one bank. Notice that due to the extra $\rho_{i}$ return on top of $m R_{2} L_{i}$, there is no risk in lending these funds to the bank that faces a refinancing need, conditional on knowing that $n_{i}$ will be able to borrow $\rho_{i}-D_{i}-W_{i}$ in total from its counterparties. A conterparty $n_{j}$, if it has decided to continue, has $W_{j}$ excess liquidity to lend to $n_{i}{ }^{4}$ Therefore, $n_{i}$ can cover $\rho_{i}$ 295 if and only if $\rho_{i} \leq D_{i}+W_{i}+\sum_{j: n_{j} \in \mathcal{N}_{i}, a_{j}=C} W_{j}$.

The timeline in Figure 1 summarizes this sequence of events and actions and the main notation we have introduced.

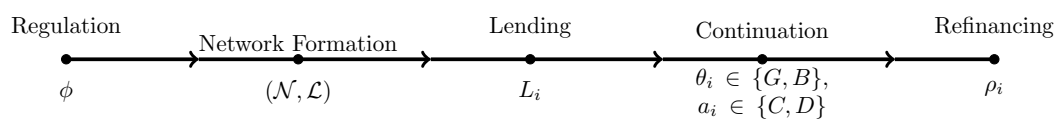

Figure 1: Timeline of events

\subsection{Interpretation of the policy parameter $\phi$.}

Notice that the parameter that determines the extent of banking regulation in our setting is $\phi$, which imposes an upper bound on the ratio of liquid assets to illiquid assets, this is $\frac{D_{i}}{L_{i}} \geq \phi$. While liquid assets, $D_{i}$ is meant to include cash, treasury bills, repos, central bank reserves, and any other asset that can be converted easily and quickly into cash, illiquid assets $L_{i}$ include loans, mortgages and other investments whose liquidation is costly and happens at a loss. Here we show that, when referring to a tightening in regulation $\phi$, we also capture a tightening in other diverse forms of banking regulatory requirements.

Reserve requirements, for example, are defined by the Federal Reserve Bank as "the amount of funds that a depository institution must hold in reserve against

\footnotetext{
${ }^{4}$ Motivated by the use of reserve requirements, banks are only allowed to lend above required reserves in the interbank market. Hence only $W_{j}$ can be used on the interbank market. This can be rationalized as the limit of a credit line. This assumption allows us to simplify the optimal choice of $L_{i}$ just by resources from bank $n_{i}$, which is otherwise intractable due to network externalities.
} 
specified deposit liabilities." In our model reserves are captured by $D_{i}$ and total liabilities by $D_{i}+L_{i}$, then reserve requirements are given by a constraint $\frac{D_{i}}{D_{i}+L_{i}} \geq \widehat{\phi} \equiv \frac{\phi}{1+\phi}$. This implies that an analysis of changes in $\phi$ is isomorphic to an analysis of changes in reserve requirements $\widehat{\phi}$.

Similarly, and even though a liquidity requirement is conceptually a constraint on the ratio of liquid to illiquid assets, as in our model, these constraints take several forms in reality. The liquidity coverage ratio (LCR), for example, is defined by the Federal Reserve Bank as "the amount of high quality, liquid assets (HQLA) such as central bank reserves and government and corporate debt that can be converted easily and quickly into cash that has to be equal to or greater than its projected cash outflows minus its projected cash inflows during a 30day stress period." Assuming that in our model the expected net cash outflow during a stress period is a fraction $\gamma$ of total liabilities, then the LCR is given by a constraint $\frac{D_{i}}{\gamma\left(D_{i}+L_{i}\right)} \geq \widetilde{\phi} \equiv \frac{\phi}{\gamma(1+\phi)}$. Again, changes in $\phi$ are isomorphic to changes in LCR $\widetilde{\phi}$.

There are other forms of liquidity requirements that are applied by regulators, such as the more recent net stable funding ratio (NSFR), which specifies a more involved timing of funding needs and definition of applicable assets, changing how $\gamma$ above is defined. From our model perspective, however, an increase in $\phi$ has the same effect than an increase in the NSFR.

Another important banking regulation is given by capital requirements, defined as "the amount of capital a bank or other financial institution has to hold as required by its financial regulator, usually expressed as a capital adequacy ratio of equity that must be held as a percentage of risk-weighted assets.? Even though in our model we do not include bank capital, imagine that instead of households depositing funds $D_{i}$ they instead hold bank stocks for $E_{i}=D_{i}$, 335 which then banks can use to invest in risky and illiquid assets, $L_{i}$. In this case capital requirements can be expressed as a condition $\frac{E_{i}}{L_{i}} \geq \phi$, and the model would be identical as the one we study here.

Finally, any other regulatory requirement that raises the costs of investing in illiquid assets relatively more than the costs of investing in liquid assets

340 effectively reduces $L_{i}$ relative to $D_{i}$ and acts as a de facto upper bound (endogenously chosen by banks) on the ratio $\frac{D_{i}}{L_{i}}$. Examples of these regulations include credit rating requirements that put constraints on the riskiness of investments or the expected returns of loans, or disclosure requirements that increase the cost of extending loans to non-standardized assets.

\section{Banking Networks}

We now solve for the equilibrium network. We work backwards and first solve the investment, continuation and refinancing stages. Then, based on these solutions, we discuss our solution concepts and characterize the equilibrium network (solving the network formation stage) as a function of an arbitrary regulatory parameter $\phi$. 


\subsection{Investment, Continuation and Refinancing Stages}

\subsubsection{Payoffs}

Refinancing stage: A bank $n_{i}$ that does not continue in the continuation stage had paid $\kappa_{l} d_{i}$ in terms of utility to form the network, has ex-post income it obtains 0 and depositors receive a bailout for $\left(1-R_{1}\right) L_{i}$. Then the bank's ex-post (utility) payoffs are $-\kappa_{l} d_{i}$.

If the bank $n_{i}$ continues and does not receive a refinancing shock, it pays back its depositors and obtains a return $\left(R_{2} L_{i}+D_{i}+W_{i}\right)-\left(L_{i}+D_{i}+W_{i}\right)=\left(R_{2}-1\right) L_{i}$.$$
\text { The bank that contines had also incurred in unility costs to form the network, }
$$
$\kappa_{l} d_{i}$, to maintain the network, $\kappa_{l}^{\prime} d_{i}$ and to manage the project, $\kappa_{c} L_{i}$. Then the continuing bank's ex-post (utility) payoffs are $\left(R_{2}-1\right) L_{i}-\left(\kappa_{l}^{\prime} d_{i}+\kappa_{c} L_{i}\right)-\kappa_{l} d_{i}$.

If the bank $n_{i}$ continues and receives a refinancing shock, then payoffs depend on whether it can obtain funds to refinance or not. If the bank can refinance the shock $\rho_{i}$, it receives $m R_{2} L_{i}-L_{i}$ ex-post payoffs, as it uses the $\rho_{i}$ extra return on top of $m R_{2} L_{i}$ to repay the credit from counterparties. Notice that interbank lending does not enter a bank's payoffs since lending to a troubled bank only happens if certain of repayment. Then this bank's ex-post (utility) payoffs are $\left(m R_{2}-1\right) L_{i}-\left(\kappa_{l}^{\prime} d_{i}+\kappa_{c} L_{i}\right)-\kappa_{l} d_{i}$. If the bank cannot refinance the

shock $\rho_{i}$, it cannot fully repay its depositors and has ex-post (utility) payoffs $-\left(\kappa_{l}^{\prime} d_{i}+\kappa_{c} L_{i}\right)-\kappa_{l} d_{i}$.

Continuation stage: Let $M_{i}$ denote the expected net return of a bank $n_{i}$ per unit of loan, net of the management costs of the network:

$$
M_{i}=\left(1-\eta_{i}\right)\left(R_{2}-1\right)+\eta_{i} F_{i}\left(D_{i}+W_{i}+\sum_{j: n_{j} \in \mathcal{N}_{i}, a_{j}=C} W_{j}\right)\left(m R_{2}-1\right)-\kappa_{c}
$$

Accordingly, the bank $n_{i}$ that continues has expected payoff (at the end of the continuation stage)

$$
\Pi(C)=M_{i} L_{i}-\left(\kappa_{l}^{\prime}+\kappa_{l}\right) d_{i} .
$$

If $n_{i}$ does not continue, its payoff is $\Pi(N)=-\kappa_{l} d_{i}$.

Investment stage: At the continuation stage, bank $n_{i}$ will best respond, so that its payoff is $-k_{l} d_{i}+\max \left\{0, M_{i} L_{i}-\kappa_{l}^{\prime} d_{i}\right\} . M_{i}$ is independent of $L_{i}$ because the continuation decision of $n_{i}$ 's counterparties depend only on the amount that $n_{i}$ can lend to them in the interbank market, which is $W_{i}$, independent of $L_{i}$. This results on the expected payoff of $n_{i}$ being weakly increasing in $L_{i}$ and that banks choose to extend as much loans as possible in the investment stage,

$$
L_{i}=\min \left\{\frac{D_{i}}{\phi}, \bar{L}_{i}\right\} \text {. }
$$

\subsubsection{Simplifying Assumptions}

For simplicity in the exposition in what follows we focus on a symmetric scenario in which all banks are identical. At the end of this section we discuss the implications of heterogeneity for network formation. 
Assumption 1. $\bar{L}_{i}=\bar{L}, D_{i}=D, W_{i}=W, \alpha_{i}=\alpha, \eta_{i}=\eta, F_{i}=F$ for all $n_{i}$.

Henceforth we denote $L(\phi)=\min \left\{\frac{D}{\phi}, \bar{L}\right\}$ for all banks. Also denote $\beta=$ $\eta\left(m R_{2}-1\right)$. Recall that the total number of counterparties of $n_{i}$ that continue is $g_{i}$, which are the banks that lend their excess liquidity to bank $n_{i}$ when in need of refinancing. Moreover define $T\left(d_{i} \mid \phi\right)$ as the "probability threshold" of $n_{i}$ for continuing. This is

$$
T\left(d_{i} \mid \phi\right)=T_{0}+\frac{d_{i} \kappa_{l}^{\prime}}{\beta L(\phi)}, \quad T_{0}=\frac{\kappa_{c}-(1-\eta)\left(R_{2}-1\right)}{\beta}
$$

Under Assumption 1 we can simplify the expression of the net return per unit of loan from (1) and rewrite the expected payoff from (2) as

$$
\begin{gathered}
\Pi\left(C, g_{i}, d_{i} \mid \phi\right)=-\kappa_{l} d_{i}+\beta L(\phi)\left[F\left(D+W+g_{i} W\right)-T\left(d_{i} \mid \phi\right)\right], \\
\Pi\left(N, g_{i}, d_{i} \mid \phi\right)=-\kappa_{l} d_{i}
\end{gathered}
$$

in case of continuation and not-continuation respectively.

If $T\left(d_{i} \mid \phi\right)>1, n_{i}$ plays $N$ regardless, as $F(\cdot) \leq 1$. Similarly, if $T\left(d_{i} \mid \phi\right)<0$ $n_{i}$ plays $C$ regardless, as $F(\cdot) \geq 0$. For $T\left(d_{i} \mid \phi\right) \in(0,1)$, define the fragility of a bank $n_{i}$ with degree $d_{i}$ as

$$
S\left(d_{i} \mid \phi\right) \equiv\left\lceil\left(F^{-1}\left(T\left(d_{i} \mid \phi\right)\right)-D-W\right) / W\right\rceil-1 .
$$

The is a measure of fragility as it captures the number of successful counterparties a bank needs to have in order to refinance the project. The higher is the fragility $S$, the more successful counterparties a bank requires in order to continue. More specifically, as shown in Figure 2 a bank $n_{i}$ plays $N$ if $g_{i} \leq S\left(d_{i} \mid \phi\right)$ and plays $C$ otherwise ${ }^{5}$

Conditional on the the total number of counterparties and those that continue, a bank $n_{i}$ is more likely to continue when $S\left(d_{i} \mid \phi\right)$ declines, which occurs when the bank has more funds on its own (higher $D$ and $W$ ), or when the threshold for refinancing decreases and the bank has more incentives to con390 tinue (higher $T\left(d_{i} \mid \phi\right)$ ). The latter happens when the net present value of the project is relatively large (high $R_{2}$ ), when the cost of continuation is relatively small (low $\kappa_{c}$ or $\kappa_{l}^{\prime}$ ) or when the probability that the project needs refinancing is relatively small (low $\eta$ ).

For expositional simplicity we assume that $F$ is uniform on $[0, P]$, which implies that $F(D+W+g W)=\max \left\{0, \min \left\{1, \frac{D+W+g W}{P}\right\}\right\}$. Moreover, we assume that the largest possible refinancing need $P$ cannot be met at any level of connectivity. The latter makes sure that every additional counterparty that continues always strictly improves the expected return.

Assumption 2. $F \sim U[0, P], P>D+W+k W$.

Before moving to solving for the equilibrium network, we specify the solution concepts.

\footnotetext{
${ }^{5}$ Here we follow the convention that $F^{-1}(t)=\infty$ for $t>1$ and $-\infty$ for $t<0$.
} 


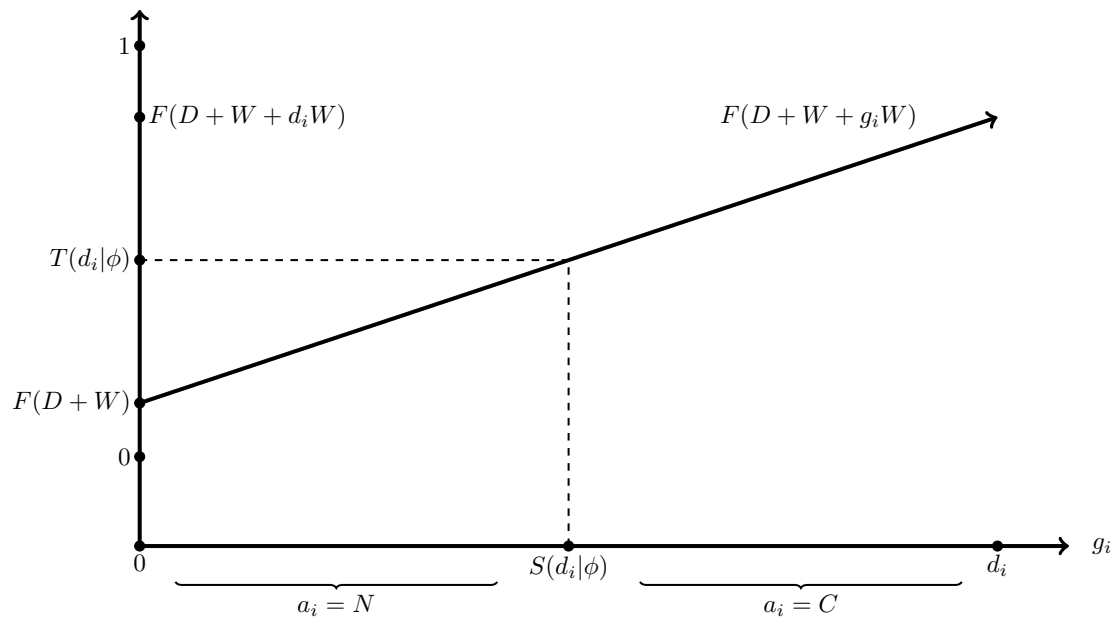

Figure 2: The decision to continue or not conditional on $d_{i}$ and $g_{i}$

\subsection{Solution Concepts}

In the continuation stage, banks with bad shocks are forced into playing $N$. Banks with good shocks play a binary game among each other. This game is supermodular. The solution concept is the cooperating equilibrium: the Nash equilibrium in which the largest set of agents, with respect to set inclusion, play $C$ among all Nash equilibria. Due to supermodularity, this equilibrium notion is well-defined. Supermodularity, by Tarski's Theorem, implies that the set of Nash equilibria is a complete lattice, and the cooperating equilibrium is the highest element of the lattice.

An alternative definition of the cooperating equilibrium can be given via a strategic contagion argument, which has a natural interpretation in financial contagion setup. Banks who receive bad shocks are forced into not continuing. After some banks become insolvent in this way, some solvent banks who are tightly connected to insolvent banks are now more likely to be illiquid: they have less likelihood of being able refinance their projects and prefer not to continue in order to save costs. These banks find find $N$ iteratively strictly dominant, and so on. This highlights the the strategic aspect of contaion in our model. The iterated elimination of strictly dominated strategies resembles a black-boxed financial contagion. Along the iteration, at the point that remaining banks can rationalize $C$, the contagion stops. The resulting profile is the rationalizable strategy profile in which anyone who can rationalize $C$ do play $C$. Supermodularity ensures that this profile is also a Nash equilibrium.

In the network formation stage, banks evaluate each network with the ex${ }_{425}$ pectation (over the shocks $\theta$ 's) of their payoffs in the cooperating equilibrium in the subsequent periods. Agents form a strongly stable network which is defined 
as follows. Consider a candidate interbank network $(\mathcal{N}, \mathcal{L})$ and a subset $\mathcal{N}^{\prime}$ of agents. A feasible deviation by $\mathcal{N}^{\prime}$ from $\mathcal{L}$ is one in which i) $\mathcal{N}^{\prime}$ can add any missing links or cut any existing links that stays within $\mathcal{N}^{\prime}$, and ii) $\mathcal{N}^{\prime}$ can cut any of the links between $\mathcal{N}^{\prime}$ and $\mathcal{N} / \mathcal{N}^{\prime}$. A profitable deviation by $\mathcal{N}^{\prime}$ from $\mathcal{L}$ is a feasible deviation in which the resulting network yields strictly higher expected payoff to every member of $\mathcal{N}^{\prime}$. An interbank network $(\mathcal{N}, \mathcal{L})$ is strongly stable if there are no subsets of $\mathcal{N}$ with a profitable deviation from $\mathcal{L}]^{6}$

The notion of network formation we employ embeds many the strategic concerns regarding the formation of links. When choosing the number of counterparties, each bank has to infer how many of them will be able to help in case of a refinancing shock, which will depend on the number of counterparties that each counterparty chooses. Moreover, multiple banks can form coalitions and coordinate their decisions regarding their links with other banks, which models another layer of strategic sophistication among banks.

\subsection{Equilibrium Network}

Payoff functions $\Pi(C)$ in (4) and $\Pi(N)$ in (5) are special cases of Erol (2016), who proves the existence and almost uniqueness of strongly stable networks in a more general setup.

Define the functions $V$ and $d^{*}$ as follows.

$$
\begin{aligned}
V(d \mid \phi) & :=\mathbb{E}_{\tilde{g}}[(1-\alpha) \times \Pi(N, \tilde{g}, d \mid \phi)+\alpha \times \max \{\Pi(C, \tilde{g}, d \mid \phi), \Pi(N, \tilde{g}, d \mid \phi)\}] \\
& =-\kappa_{l} d+\alpha \beta L(\phi) \mathbb{E}_{\tilde{g}}\left[\max \left\{0, F(D+W+\tilde{g} W)-T\left(d_{i} \mid \phi\right)\right\}\right]
\end{aligned}
$$

where $\tilde{g} \sim G[\cdot, d, \alpha]$ for $G$ is defined as the c.d.f. of binomial distribution with $d$ trials and $\alpha$ success probability. $V$ can be thought of as a hypothetical payoff function for a single bank with degree $d$ that supposes that its counterparties default if and only if they received bad shocks. In other words, $V$ is the payoff function absent contagion. Define $d^{* *}(\phi):=\operatorname{argmax}_{d \in \mathbb{Z}^{*}} V(d \mid \phi)$ the hypothetical optimal degree for a single bank if there was no contagion. Since $F(\cdot) \leq 1, d^{* *}$ is generically well-defined. As there is an upper bound on the number of counterparties, the relevant optimal degree is

$$
d^{*}(\phi):=\operatorname{argmax}_{d \leq k-1} V(d \mid \phi) .
$$

${ }_{445}$ Clearly $d^{*}(\phi) \leq d^{* *}(\phi)$. If $d^{* *}(\phi) \leq k-1$, then $d^{*}(\phi)=d^{* *}(\phi)$. The following proposition characterizes the optimal network degree.

Proposition 1 (Network Formation). Let $k(\phi) \in\left[0, d^{*}(\phi)\right]$ be given by $k \equiv$ $k(\phi)\left(\bmod d^{*}(\phi)+1\right)$. If $T\left(d^{*}(\phi) \mid \phi\right)>F(D+2 W)$, there exists a unique strongly

\footnotetext{
${ }^{6}$ This network formation solution concept can be microfounded by a proposal game. Each bank pays $c>0$ to make a proposal to another bank. Mutual proposals turn into links, and $\operatorname{cost} c$ is refunded to both. One-sided proposals do not turn into links, and $c$ is lost. After being formed, links represent secondary market trades that serve to provide liquidity to banks. The strong Nash equilibria of this game corresponds to strongly stable networks. See Erol and Vohra (2016) for more details.
} 
stable network which consists of $(k-k(\phi)) /\left(d^{*}(\phi)+1\right)$ disjoint cliques of order $d^{*}(\phi)+1$ and some more disjoint cliques of smaller order ${ }^{7}$ If $T\left(d^{*}(\phi) \mid \phi\right)<$ $F(D+2 W)$, the network described above is strongly stable. In any other strongly stable network, all but at most $d^{*}(\phi)$ banks have degree $d^{*}(\phi)$.

In the cooperating equilibrium, if less than $S\left(d^{*}(\phi) \mid \phi\right)$ banks in a clique get good shocks, all $d^{*}(\phi)+1$ banks in the clique play $N$. If more than or equal to ${ }_{455} S\left(d^{*}(\phi) \mid \phi\right)$ banks in a clique get good shocks, banks with bad shocks play $N$ and banks with good shocks play $C$.

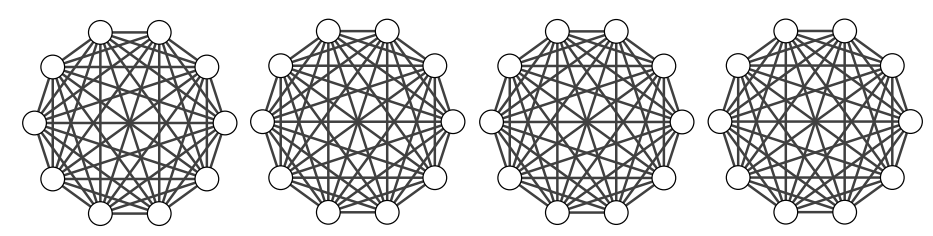

Figure 3: Cliques

Proof.

Here we show that the payoff functions $\Pi$ can be modified appropriately to satisfy the assumptions that guarantee the main theorem in Erol (2016).

Define $\Pi^{*}\left(a_{i}, f_{i}, d_{i}, \theta_{i}\right)$ as

$$
\Pi^{*}\left(a_{i}, f_{i}, d_{i}, \theta_{i}\right)= \begin{cases}\Pi\left(a_{i}, d_{i}-f_{i}, d_{i}\right) & \theta_{i}=G \\ \Pi\left(N, d_{i}-f_{i}, d_{i}\right) & \theta_{i}=B, a_{i}=N \\ \Pi\left(N, d_{i}-f_{i}, d_{i}\right)-1 & \theta_{i}=B, a_{i}=C\end{cases}
$$

For this altered function $\Pi^{*}$, even if bad banks were allowed to play $C$, they would never do it since it is strictly dominant to play $N$ if $\theta_{i}=B$. Hence the cooperating equilibrium of the game with payoff function $\Pi^{*}$ where bad banks are also allowed to play $C$ correspond to the cooperating equilibrium of the game with payoff function $\Pi$ where bad banks are forced to play $N$.

The assumptions in Erol (2016) are satisfied by $\Pi^{*}$. First, counterparty failures hurt: $\Pi^{*}\left(C, f_{i}, d_{i}, G\right)$ must be strictly decreasing in $f_{i}$. Notice that $P>D+W+k W$ and $D+W>0$ makes sure that $F\left(D+W+g_{i} W\right)$ stays in the interior of the support of $F$. Hence $\Pi\left(C, g_{i}, d_{i}\right)$ is strictly increasing in $g_{i}$, making $\Pi^{*}\left(C, f_{i}, d_{i}, G\right)$ strictly decreasing in $f_{i}$. This assumption is only relevant for uniqueness, not for strong stability. Second, $N$-payoffs are independent of $f_{i}$ : This is clearly satisfied since $\Pi\left(N, g_{i}, d_{i}\right)=-\kappa_{l} d_{i}$ is independent of $g_{i}$. Third, $N$ is a strictly dominant strategy if $\theta_{i}=B$ : This is guaranteed by construction.

\footnotetext{
${ }^{7}$ See Erol $(2016)$ for the exact order(s) of the remaining smaller clique(s). It needs heavy notation to describe the remainder of the network.
} 
Then the main theorem in Erol (2016) can be applied, and the unique strongly stable network is given by disjoint cliques of order $d^{*}(\phi)+1$.

Figure 3 illustrates the structure of the equilibrium network (in this example, four cliques of degree nine, this is with 10 counterparties each). Notice that this structure eliminates second order counterparty risk: the risk that a bank may incur losses due to some of its counterparties that choose to not continue because of their own counterparties that do not continue. By forming cliques

480 of an optimal size, banks reach a satiation point in terms of desired number of counterparties while they do not face any risk of contagion further and beyond what is inevitable, i.e. the risk that their immediate counterparties get bad shocks. The particular clique structure may seem unrealistic as a description of interbank networks. However, as we discuss in a remark at the end of next section, with heterogeneity across banks, they would form core-periphery networks but the qualitative fragility result we obtain later from this simpler symmetric version carries on.

If $T\left(d^{*}(\phi) \mid \phi\right)<F(D+W)$ there is no contagion (meaning that there is naturally no second order counterparty risk) as the available funds from the bank 490 facing the shock is enough to cover the refinancing need, then the bank continues even if none of its counterparties continue. If $F(D+W)<T\left(d^{*}(\phi) \mid \phi\right)<F(D+$ $2 W)$ there is minimal contagion, as it is enough that one counterparty continues for the bank in need of refinancing continues, then the bank continues unless none of its counterparties continue. The more interesting case is $T\left(d^{*}(\phi) \mid \phi\right)>$ $495 F(D+2 W)$, as the bank with refinancing needs continues if and only if more than a counterparty continues. Proposition 1 shows that in this last and more relevant case the strongly stable network is unique.

\section{Network Reactions to Banking Regulations}

In this section we discuss how the banking network changes with changes in the liquidity requirement $\phi$, and show that above a certain critical threshold the network drastically collapses.

In what follows, we ignore integer problems between $d^{*}(\phi)+1$ and $k$ and focus on networks that consist of disjoint cliques of order $\left.d^{*}(\phi)+1\right]^{8}$

We focus on the expected number of banks that choose $N$ as our main notion

505 of systemic risk. For arbitrary networks this is hard to pin down analytically in closed form. By Proposition 1 we can compute even the distribution of the number of banks that play $N$ on the unique strongly stable network that is formed.

\footnotetext{
${ }^{8}$ The results formally follows by assuming that $\phi$ is selected from a finite subset $X$ of $[0,1]$, and $k$ is divisible by $\prod_{\phi \in X}\left(d^{*}(\phi)+1\right)$. Intuitively, though, for any $\phi$ the remainder cliques represent a small fraction of the economy and they are isolated from the rest of the network, hence they have negligible impact on the comparative statics.
} 
Corollary 1 (Systemic Risk). For a given $\phi$, the expected fraction of banks that play $N$ is

$$
1-\alpha+\alpha G\left[S\left(d^{*}(\phi) \mid \phi\right)-1, d^{*}(\phi), \alpha\right],
$$

and the probability that all banks play $N$ is

$$
G\left[S\left(d^{*}(\phi) \mid \phi\right), d^{*}(\phi)+1, \alpha\right]^{\frac{k}{d^{*}(\phi)+1}} .
$$

Recall that $G\left[S\left(d^{*}(\phi) \mid \phi\right)-1, d^{*}(\phi), \alpha\right]$ measures the probability that, out of the $d^{*}$ counterparties that a good bank has, not enough succeed in order for the bank to continue (given the bank needs $S\left(d^{*}(\phi) \mid \phi\right)$ of the $d^{*}$ counterparties to succeed in order to continue).

If tighter regulations decrease the equilibrium number of counterparties in the network, $d^{*}(\phi)$, then the level of systemic risk in the economy may increase. In what follows we indeed show that an increase in $\phi$ reduces $d^{*}$ smoothly until it reaches a threshold above which $d^{*}$ suddenly collapses to 0 , a situation we denote empty network.

The optimal number of counterparties for a bank will be given by the degree that maximizes its value function. Define the resilience of a bank as,

$$
R(d \mid \phi):=d-S(d \mid \phi)-1 .
$$

which increases with the number of counterparts a bank has and decreases with the fragility of the bank (the number of successful counterparties the bank requires to continue). After some algebra, the value $V(d \mid \phi)$ is given by:

$$
\begin{gathered}
V(d \mid \phi)=A L(\phi) G(R(d \mid \phi), d, 1-\alpha)+ \\
d \times\left[-\kappa_{l}-\alpha \kappa_{l}^{\prime} G(R(d \mid \phi), d, 1-\alpha)+B L(\phi) G(R(d \mid \phi), d-1,1-\alpha)\right],
\end{gathered}
$$

where

$$
\begin{gathered}
A=\alpha \beta\left(F(D+W)-T_{0}\right)=\alpha\left[-\kappa_{c}+(1-\eta)\left(R_{2}-1\right)+\eta \frac{(D+W)}{P}\left(m R_{2}-1\right)\right], \\
B=\frac{\alpha^{2} \beta W}{P} .
\end{gathered}
$$

This characterization of the value function as a function of the network degree, which according to Proposition 1 is based on cliques, defines the individual optimal number of counterparties that a bank would choose to borrow in the interbank lending market in case it faces a refinancing need. We describe next the shape of this value function, its maximum $d^{*}(\phi)$ and how it changes as the regulation parameter $\phi$ changes.

While the coefficient $A$ governs the behavior of an isolated bank (without counterparty or degree $d=0$, the coefficient that multiplies $d$ nicely decomposes the costs and benefits of having additional counterparties.

530 This expression for the value function is suggestive of discontinuous dynamics. Imagine first that the probability that a good bank can continue because 
not enough counterparties are successful, $G$, is fixed. It is clear that, as regulation tightens ( $\phi$ increases) the bank invests less $(L(\phi)$ decreases) and has less incentives to have a counterparty that helps to refinance a small project in distress. When $\phi$ is relatively small the coefficient that multiplies $d$ in the previous expression may be positive, and banks want to have all other banks as counterparties (complete network). When $\phi$ is relatively large the coefficient may be negative, in which case the bank does not want any counterparty. Given the monotonicity of the coefficient that multiplies $d$ when $G$ is fixed, this captures 540 a trivial bang-bang solution. Our model, however, captures a more intricate fragility, one that is robust to heterogeneity across counterparties. We show that the expectation of idiosyncratic bad shocks and the resulting expectation of inefficient cascades of ex-post failures induce banks, ex-ante, to strategically and jointly reduce their number of their counterparties until a point at which the whole network collapses suddenly.

The probability that the bank can obtain enough refinancing funds from counterparties to justify continuation, $G$, depends however on both $\phi$ and $d$. How does the value function change with the number of counterparties? This is illustrated in each panel of Figure $4^{9}$ Value functions are decreasing in $d$ ${ }_{50}$ when the probability of not obtaining enough funds from counterparties, $G$, is fixed, as the bank has to pay $\kappa_{l}$ for each additional counterparty. This is clearly the case when $d$ is small, as there are so few counterparties that $G=0$ or when $d$ is large, as there are so many counterparties that $G=1$. When $d$ is intermediate, however, an additional counterparty increases $G$, making more likely to find enough funds to cover refinancing needs. When the increase in the probability of taking the project to maturity is higher than the cost of creating the link, then the value function may increase in this intermediate region. Since $G$ is probabilistically more reactive to $\phi$, in this region extra links are rapidly becoming more beneficial up to a probabilistic satiation point. Therefore, $V$ is 560 hump shaped in this middle region, and the peak of the hump is the optimal degree $d^{*}$. The peak is achieved at a value of $d$ with large resilience $R$ and $G$ very close to 0 .

How does the optimal number of counterparties, $d^{*}$, changes with regulation, $\phi$ ? We illustrate this relation comparing the panels in Figure 4. As $\phi$ increases, ${ }_{565}$ the value function for all $d$ and the optimal degree $d^{*}$ decrease, generating an initial smooth change in the level of connectivity $d^{*}$. This smooth transition occurs until a point in which the peak of the value function that determines $d^{*}$ becomes negative. At that point the solution is $d^{*}=0$, as in the last panel of the figure.

This analysis illuminates that a simpler model with two banks and a bangbang solution misses important elements that only arise in the presence of networks. Banks do take the resilience and connectivity of other banks in the system into account when choosing their own level of connectivity. Changes in

\footnotetext{
${ }^{9}$ The parameters used to construct Figure 4 are $k=100, \alpha=0.9, \bar{L}=3000, \eta=1 / k, W=$ $10, R_{1}=0, R_{2}=20, m=1, \kappa_{d}=1, D=15, P=615, \kappa_{c}=18.905, \kappa_{l}=0.03, \kappa_{l}^{\prime}=0.02$.
} 
regulation do not only modify the individual benefits of having counterparties but also the connectivity choices of other banks, and then their likelihood of being successful counterparties. Intuitively, the phase transition happens because, as regulation increases, and the size of investments decline, each bank is less likely to form counterparties, but this implies that each counterparty is less likely to continue and to help refinancing a potential shock. This makes a 580 counterparty less attractive, which introduces a non linear feedback effect that leads to a sudden collapse after a critical $\phi$ level. Formally, we prove the phase transition in an Online Appendix for a special case.
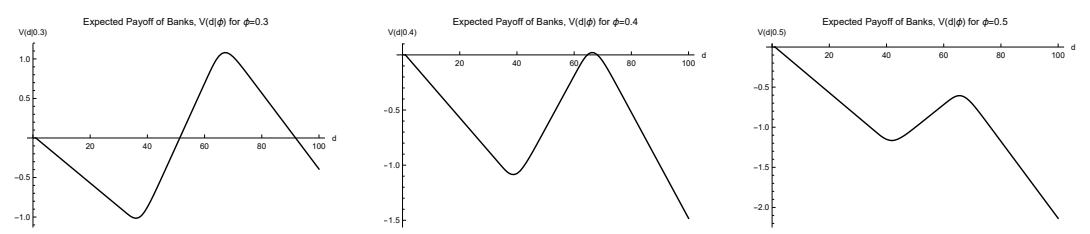

Figure 4: $V(d \mid \phi)$ as $\phi$ increases

Naturally, if $k<d^{*}$, the upper bound $k-1$ on the number of counterparties binds before reaching the satiation point, and the realized network will be complete (a single clique with all banks as members) which will suddenly collapse to an empty network after $\phi$ goes above a certain threshold. Once the network is empty, no bank continues: this is always the case for bad banks, while good banks liquidate their projects too because the likelihood of a refinancing shock is large enough compared to the chances to refinance, such that it does not compensate to pay continuations costs 10

Remark on heterogeneity across banks: The symmetric clique structure may seem unrealistic as a description of interbank networks. This particular structure, however, is a simplification of a broader and more general structure when banks are heterogenous that do not modify the main fragility insight of 595 the network. For example if some banks are large in terms of their deposit base while others are small, the network would display a core-periphery structure where banks in the periphery are lumped into cliques modulo their links with the core. These cliques would still have a certain size and similar qualitative results would hold in the size of the cliques in the periphery. Another ${ }_{600}$ way of introducing heterogeneity is along the lines of Farboodi (2015): some banks have access to investment opportunities and some do not. In a version of the model in which banks can make ex-ante side payments or links are directed, banks with investment opportunities would pay for links with banks without the

\footnotetext{
${ }^{10}$ Why do banks invest knowing that they never continue? Banks are indifferent between investing $L=0$ and obtain 0 profits or investing any other amount and obtain 0 after liquidation. This is just an artifice of the assumption that can be easily relaxed if assuming that there is a small chance the project is guaranteed, at the beginning of the continuation stage, not to suffer any refinancing shock at the refinancing stage.
} 
investment opportunities, and aside of these links, banks with investment opportunities would form cliques among each other, again leading to core-periphery network with similar qualitative results in the size of cliques across the banks with investment opportunities.

\section{Optimality of a Network-Conscious Regulator}

The analysis so far has been positive and focused on understanding how the policy affects the network structure and the resulting systemic risk. Here we obtain the optimal liquidity requirement that a network-concious regulatior, who understand the effects of regulation in the network structure, would introduce.

We introduce two assumptions, which we relax at the end of the section, to simplify the exposition. First, we assume that the number of banks is not too

615 large. As a consequence, the upper bound binds before the satiation point so that when a network exists, it is complete, and then falls to the empty network at the tipping point. Second, we assume that banks individual deposits of banks are not too large and they need each other. In particular they are not likely enough refinance a project in isolation, so that isolated banks play $N$ (in case of not having any counterparty).

Figure 5 shows that the network collapses from a complete network $\left(d^{*}=\right.$ $100)$ to an empty network $\left(d^{*}=0\right)$ at $\phi=0.2511$ The second panel in the figure shows the evolution of fragility in the network. As $\phi$ increases towards 0.25 , the number of counterparties that are required to be successful for a bank

${ }_{625}$ to increases from 50 to 65 , until the network collapses. Finally, the last panel shows the expected fraction of banks that choose not to continue, going from $10 \%$ (the fraction of bad banks) when the network is complete, to $100 \%$ when the network is empty.
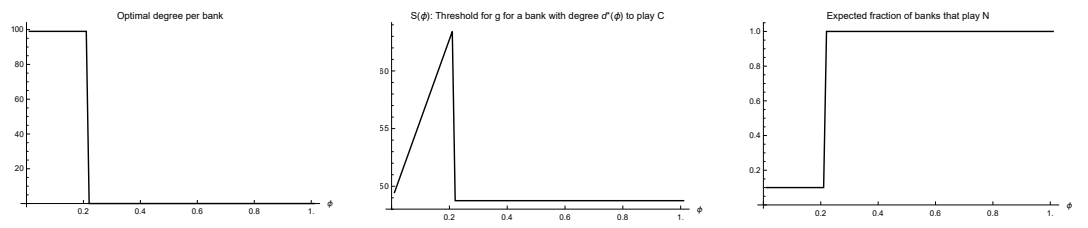

Figure 5: Optimal degree $d^{*}(\phi)$, induced fragility $S$, and resulting systemic risk

\subsection{Notion of Welfare}

630

To define and decompose welfare, we assume that banks have all the bargaining power, capturing all profits when continuing, and limited liability, not suffering any loss when not continuing. Instead, in this last case the government

\footnotetext{
${ }^{11}$ The parameters used to construct the Figures 56 are $k=100, \alpha=0.9, \bar{L}=3000, \eta=$ $1 / k, W=10, R_{1}=0, R_{2}=20, m=1, \kappa_{d}=1, D=15, P=1025, \kappa_{c}=18.905, \kappa_{l}=$ $0.03, \kappa_{l}^{\prime}=0.02$.
} 
has to resort on distortionary bailouts to cover banks' promises to depositors. As deposits are always repaid, either by the bank or the government, households do not count for welfare.

We can then decompose welfare in two parts. One is the banking component: the part of welfare that is internalized by banks, which is the surplus from production in case of continuation. The other is the bailout component: the part of welfare that is not internalized by banks, and consists of direct and ${ }_{640}$ indirect costs the government incurs to cover the business depositors in case of no continuation. More specifically,

Banking component: The profits from all bad projects and from all good projects that do not continue are 0 . The expected profits from all good projects that continue are $\left(R_{2}-1\right) L$. Let $g^{*}$ denote the total number of good banks that choose to continue: $g^{*}=\left|\left\{n_{i}: a_{i}=C, \theta_{i}=G\right\}\right|$. The expected total bank profits in the system is then $\left(g^{*}-\mathcal{I}\right)\left(R_{2}-1\right) L$, where $\mathcal{I}$ is an indicator function that takes the value 1 if a bank has a refinancing need that cannot be covered (and the project is then lost), and 0 otherwise. Including the total utility costs of forming the network $\left(k \kappa_{l} d^{*}\right)$, the utility costs of managing the network for all good banks continuing $\left(g^{*} \kappa_{l}^{\prime} d^{*}\right)$ and the utility costs of managing the continuing projects $\left(g^{*} \kappa_{c} L\right)$. The banking component is then

$$
\left(g^{*}-\mathcal{I}\right)\left(R_{2}-1\right) L-k \kappa_{l} d^{*}-g^{*}\left(\kappa_{c} L+\kappa_{l}^{\prime} d^{*}\right)
$$

Bailout component: Let $f^{*}$ denote the total number of good banks that choose not to continue: $f^{*}=\left|\left\{n_{i}: a_{i}=N, \theta_{i}=G\right\}\right|$. That means $k-f^{*}-g^{*}$ banks receive bad shocks, so that government covers $\left(k-f^{*}-g^{*}\right) L$ due to bad shocks. $f^{*}\left(1-R_{1}\right) L$ is the total amount covered by the government due to good banks that decide not to continue. Moreover, $\mathcal{I} L$ is covered due to the refinancing shock. The direct effect of bailouts, not internalized by banks, is the amount of deposits to be covered. The indirect effect comes from distortionary costs to cover these deposits, $\kappa_{d} \geq 1$ per unit of bailout. The bailout component is then

$$
-\kappa_{d}\left[\left(k-f^{*}-g^{*}\right) L+f^{*}\left(1-R_{1}\right) L+\mathcal{I} L\right] .
$$

Both components are influenced by policy $\phi$ via three main channels. First, the direct and well-known investment channel, as $L(\phi)=\min \left\{\frac{D}{\phi}, \bar{L}\right\}$. The project scale has a direct effect both on banks' profits and on government ${ }_{645}$ bailouts. Second, the contagion channel, captured by the number of good banks who choose not to continue, $f^{*}$, and by the good bank that continues but suffers a renegotiation need that cannot be covered in the network, $\mathcal{I}$. Third, the management channel which lumps the utility costs of management and link formation incurred by banks.

The number of banks with good shocks is $f^{*}+g^{*}, \alpha k$ in expectation at the regulation stage. Defining $f^{* *}=\mathbb{E}\left[f^{*}\right]$ and $\mathcal{I}^{*}=\mathbb{E}[\mathcal{I}]$ where expectations are taken at the regulation stage, expected welfare can be decomposed into components and channels as follows as in Table 1. 


\begin{tabular}{|c|c|c|}
\hline Welfare & Banking component & Bailout component \\
\hline (Net) Investment channel & $\alpha k\left(R_{2}-1\right) L$ & $-\kappa_{d}(1-\alpha) k L$ \\
\hline Contagion channel & $-f^{* *}\left(R_{2}-1\right) L-\mathcal{I}^{*}\left(m R_{2}-1\right) L$ & $-\kappa_{d}\left[f^{* *}\left(1-R_{1}\right) L+\mathcal{I}^{*}\right] L$ \\
\hline Management channel & $-k \kappa_{l} d^{*}-\left(\alpha k-f^{* *}\right)\left(\kappa_{c} L+\kappa_{l}^{\prime} d^{*}\right)$ & - \\
\hline
\end{tabular}

Table 1: Components of ex-ante welfare

\subsection{Optimal regulation and phase transition}

655 can identify the level of $\phi^{*}$ that maximizes welfare. The optimal liquidity requirement is $\phi^{*}=0.25$, the threshold point at which the network transitions from complete to empty, as in Figure 5. but where a network exists. The reason is that a network allows more banks to continue, even when some banks may suffer refinancing shocks and not continue afterwards. Large liquidity requirements suffocate banks enough such that they not only have to reduce their investment scales but also choose not to continue them.

Figure 6 illustrates this result, welfare increases for all $\phi$, with a discontinuity at the point in which the network collapses. Welfare increases with $\phi$, as more regulation reduces the size of bailouts, except at $\phi^{*}$, point at which the network collapses and there is a sudden jump in the number of bailouts. This result suggests that, if the government has some uncertainty about fundamentals, it might be too risky to try to set the exact optimal policy at the kink since a slight overshooting can result in large unintended welfare cost and a collapse of

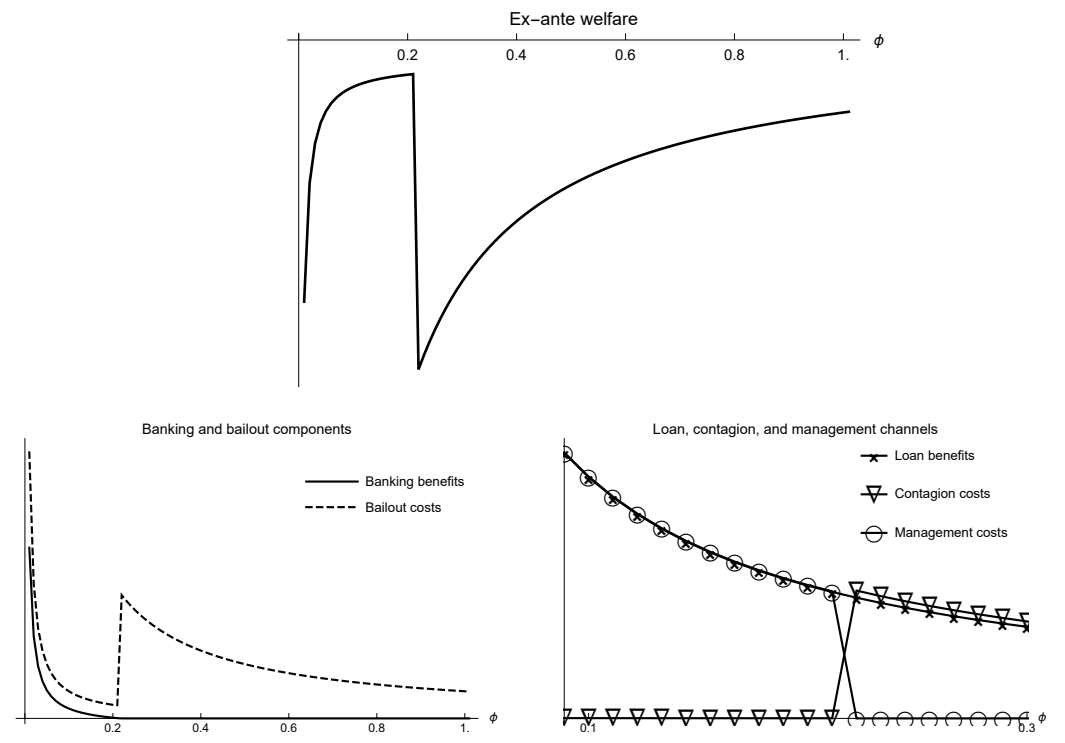

Figure 6: Welfare in $\phi$, and its components and channels 
In Figure 6, we dissect welfare into its components and channels. The banking component declines with $\phi$ because investments decline with $\phi$. Since the scale of projects decline, the amount that bailouts have to cover also decline, but only initially, when the network operates fully. At the threshold when the network collapses, bailout needs increase discontinuously because no bank chooses to create a network and to continue. The government suddenly has to cover smaller projects but for many more banks. This is what we called the contagion channel. The second panel of the figure also shows the sudden reduction in management costs, which still are not large enough to compensate the increase in the higher needs for bailouts.

\subsection{Relaxing Assumptions.}

\subsubsection{Large number of banks}

In the previous welfare analysis we have assumed that $k$ is not too large so that, when exists, a network is complete. The reason was that the largest shock ${ }_{685} P$ was sufficient to force any bank into default. Therefore, there was never a satiation point in terms of the number of desired counterparties. Then banks wanted as many links as possible leading to a complete network.

Here we show that this assumption is not critical for the results. If $P$ is not as large there is a satiation point in terms of the number of counterparties demanded to satisfy a large probability of surviving a possible refinancing shock (typically a probability close to 1 ). This generates a dense, but not complete, network ${ }^{12}$ Changes in regulation now smoothly changes the satiation point. In Figure 7 we show how the satiation point $d^{*}$ slowly falls as regulation becomes tighter. Still, the network suddenly collapses at a point $\phi=0.45{ }^{13}$

695 Notice that in this example welfare starts falling sharply just before the transition point of the network, not exactly at the transition point. The reason is that the source of phase transition in this example is the probabilistic source. Larger $\phi$ reduces the size of investments, decreasing fragility $S$, as a bank needs less successful counterparties to refinance a project in distress. They react to 700 this change by decreasing their degree slowly. As $\phi$ keeps growing, however, it becomes impossible at some point to face a refinancing shock almost with certainty. At this point, the contagion becomes a serious ex-ante problem and many banks are expected to liquidate their good projects, as can be seen in the plot of the expected fraction of banks that play $N$ in Figure 7 When $\phi$ 705 reaches a higher threshold that fragility is insurmountable and there is almost certainty of liquidating a good project, with banks stop forming links. The optimal degree falls to zero at $\phi=0.45$ but banks' payoffs and welfare starts falling very sharply in advance due to contagion.

\footnotetext{
${ }^{12}$ The only small technical complication of allowing a small $P$ (more specifically, from assuming $P<D+W+k W$ ) is that, from the main theorem of Erol (2016), the described network is still strongly stable but not the unique strongly stable network.

${ }^{13}$ The parameters used to construct the Figure 7 are $k=100, \alpha=0.9, \bar{L}=3000, \eta=$ $1 / k, W=10, R_{1}=0, R_{2}=20, m=1, \kappa_{d}=1, D=15, P=615, \kappa_{c}=18.905, \kappa_{l}=$ $0, \kappa_{l}^{\prime}=0.05$.
} 

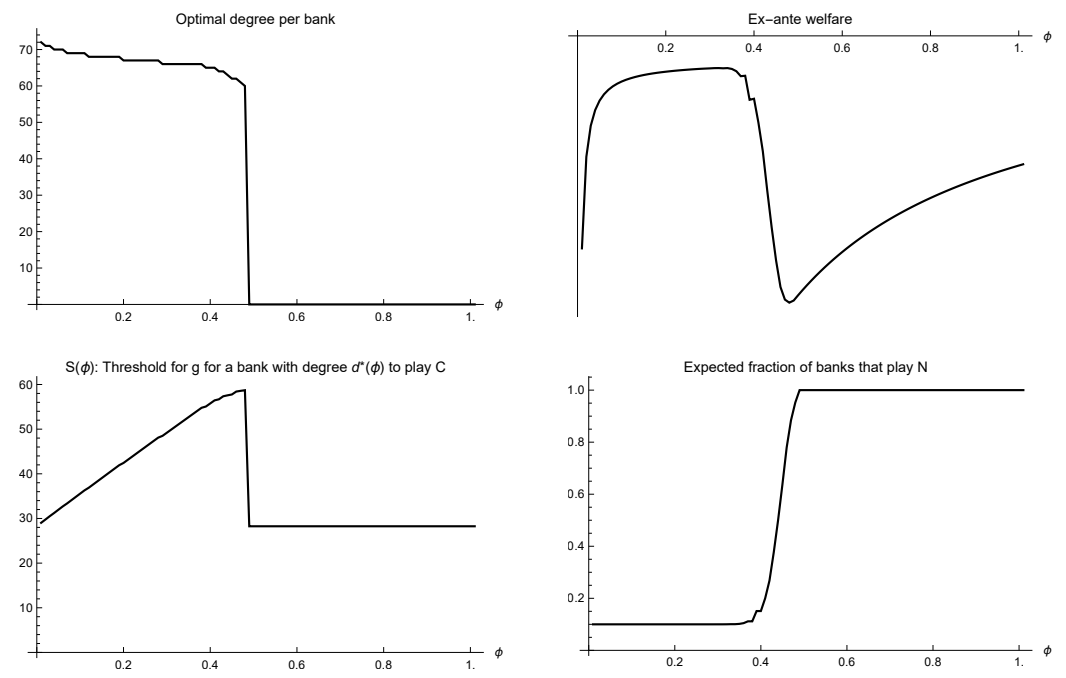

Figure 7: Smooth change in the network structure when the largest shock is not too large, and resulting welfare, fragility, and systemic risk

\subsubsection{Deposits are large enough}

When deposits are small so that individual banks' own resources are small compared to $P$, isolated banks are destined to play $N$, which amplifies bailout costs. Here we show that even when $P$ is relatively small (more specifically, $\left.D+W>P T_{0}\right)$ such that banks continue even without counterparties, welfare may still feature sharp declines around a transition point in which networks

715 stop operating. As illustrated in Figure 8 however, here the optimal level of regulation is not at the transition point of $\phi=0.05$ (as in the previous cases) but instead very close to $\phi=0.14$

\section{Mistakes of a Network-Blind Regulator}

Here we discuss the mistakes that a network-bling regulator, who does not consider that the network structure reacts to $\phi$, makes when trying to naively maximize welfare by taking the network structure as given at the observed level when deciding regulation.

More specifically, we have shown that for any arbitrary network in cliques with degrees $d$ and arbitrary level of liquidity requirement $\phi$, there is a welfare level $W(d, \phi)$. Suppose that the economy is at a status quo level of liquidity requirements $\phi_{0}$, not necessarily optimal at this point, that induce an optimal

\footnotetext{
${ }^{14}$ The parameters used to construct the Figure 8 are $k=100, \alpha=0.9, \bar{L}=3000, \eta=$ $1 / k, W=10, R_{1}=0, R_{2}=20, m=1, \kappa_{d}=1, D=1, P=1010, \kappa_{c}=18.791, \kappa_{l}=$ $0.03, \kappa_{l}^{\prime}=0.02$.
} 


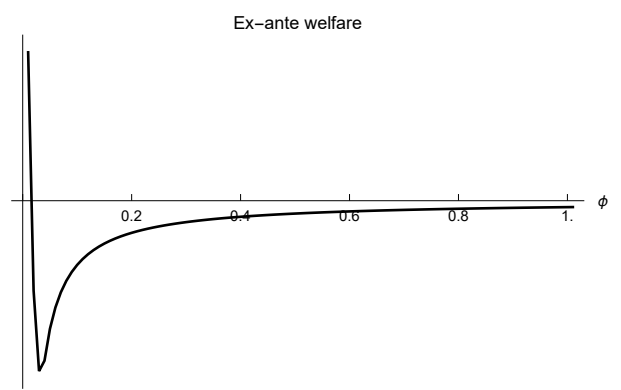

Figure 8: Induced welfare when isolated banks are sufficiently liquid

reaction of banks into a strongly stable network with optimal degree $d_{0}=d^{*}\left(\phi_{0}\right)$. The status quo welfare is then $W\left(d^{*}\left(\phi_{0}\right), \phi_{0}\right)$.

Assume now the government decides to adjust $\phi$ to an optimal level given the observed network degree $d^{*}\left(\phi_{0}\right)$. If the government takes into account network reactions, as in the previous analysis, then the government maximizes $W\left(d^{*}(\phi), \phi\right)$ over $\phi$ and $\phi$ is adjusted to $\phi^{* *}=\operatorname{argmax}_{\phi}\left\{W\left(d^{*}(\phi), \phi\right)\right\}$ and all banks have degree $d^{* *}=d^{*}\left(\phi^{* *}\right)$.

If, however, government does not acknowledge the reaction of the interbank network to the changes in policy and takes the network with degrees $d_{0}$ as given and fixed, what would be the unintended consequences of such a network-blind policy? Formally, the government takes the network in clique structure with degrees $d_{0}$ as given, and choose a policy $\phi^{*}\left(d_{0}\right)=\operatorname{argmax}_{\phi}\left\{W\left(d_{0}, \phi\right)\right\}$ which maximizes welfare for this fixed network with $d_{0}$. But then, the network reacts to this policy change and the degrees become $d^{*}\left(\phi^{*}\left(d_{0}\right)\right)$. The realized welfare is then $W\left(d^{*}\left(\phi^{*}\left(d_{0}\right)\right), \phi^{*}\left(d_{0}\right)\right)$. The immediate cost of the network-blind policy is captured by the wedge

$$
W\left(d_{0}, \phi_{0}\right)-W\left(d^{*}\left(\phi^{*}\left(d_{0}\right)\right), \phi^{*}\left(d_{0}\right)\right),
$$

while the opportunity cost of the network-blind policy is captured by the wedge

$$
W\left(d^{* *}, \phi^{* *}\right)-W\left(d^{*}\left(\phi^{*}\left(d_{0}\right)\right), \phi^{*}\left(d_{0}\right)\right) .
$$

Figure 9 which is based on the benchmark simulation in the previous section, illustrates the main result. A network-blind regulator who starts at a high status quo $\phi_{0}$ takes the empty network $d^{*}=0$ as given, then naively thinking that welfare in reaction to regulation follows the dashed line (labeled by "NetworkBlind: Sparse"). A network-blind regulator who starts at a low status quo $\phi_{0}$ on the other hand takes the complete network $d^{*}=k-1$ as given, then naively 740 thinking that welfare in reaction to regulation follows the dotted line (labeled by "Network-Blind: Dense"). A network-conscious regulator follows the same solid line as in Figure 6 .

Imagine that the status quo is given by $\phi_{0}=0.1$, for instance, in which the observed network is dense. A network-blind government would think that 

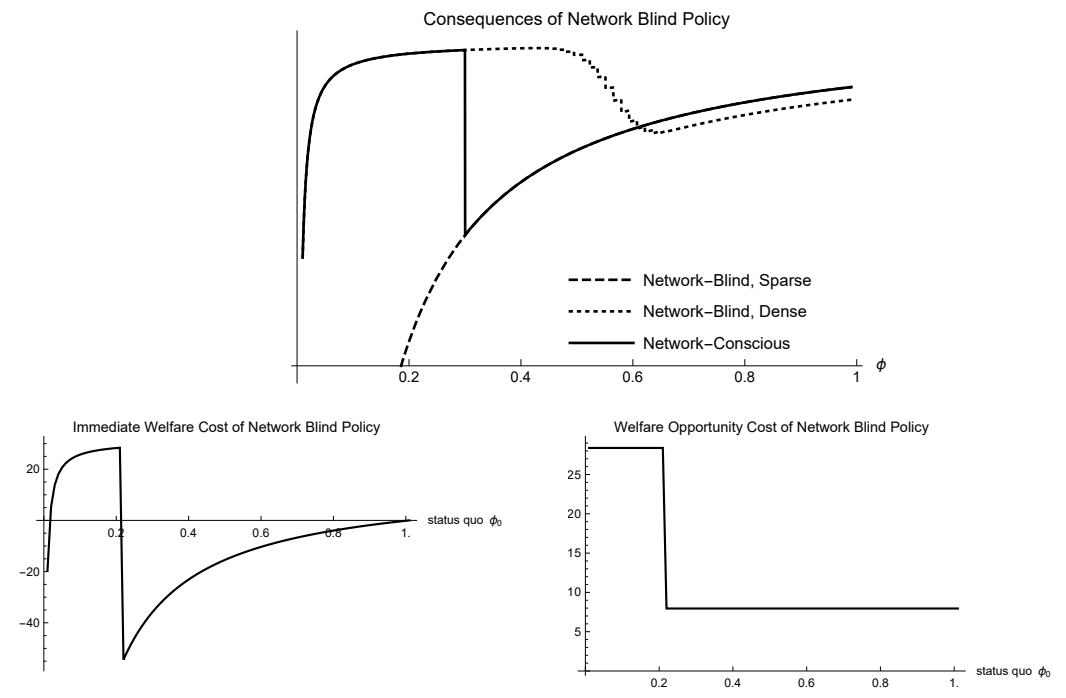

Figure 9: Network-conscious welfare and network-blind welfare for given networks, and the costs network-blind regulation

welfare is maximized at around $\phi=0.5$. However, once a liquidity requirement of $\phi=0.5$ is implemented the network reacts by becoming sparse and the realized welfare becomes much lower than both the intended level and the starting status-quo level.

Imagine, in contrast, that the status quo is given by $\phi_{0}=0.8$, for example, in which the observed network is sparse. A network-blind government would think that welfare can be maximized at $\phi=1$. In this case the welfare improves upon the status quo as the network does not react to this policy. The opportunity cost is still positive though since the optimal for a network-conscious policy is a much lower requirement, $\phi^{*}=0.25$.

755 The immediate welfare costs and welfare opportunity costs of a networkblind policy for any status quo $\phi_{0}$ are plotted in Figure 9. The first panel shows the comparison of the status-quo welfare with respect to the networkblind policy welfare realization. For low liquidity requirements the status-quo always displays higher welfare as moving to a network-blind policy implies a network collapse. For high liquidity requirements the status-quo always displays lower welfare as the status-quo is already given by no network. The second panel shows the comparison, for any status-quo, between the welfare that would be achievable by a network-conscious policy relative to a network-blind policy. Not surprisingly, this difference is always positive, and larger among low levels of liquidity requirements in status-quo. 


\section{Conclusions}

The discussion about the optimal level of liquidity requirements, and more generally about optimal banking regulations, has generated a fruitful recent debate among academics and policymakers alike, particularly in light of many

770 role that a dense interbank network and complex counterparty relationships have played during the recent crisis, it is surprising the scarce discussion about how the proposed regulations would affect the density and topology of interbank lending relations and the banking network more generally.

We show that tightening liquidity requirements above a critical threshold may induce a sudden collapse in interbank relationships, discontinuously decreasing insurance across banks to face liquidity and refinancing shocks. This is an endogenous network reaction that should be taken into account by regulators when proposing further tightening of liquidity requirements. In other words, a network-blind tightening in regulation may induce a discontinuous increase in systemic risk: even though the bailouts that are needed are smaller, more banks know they cannot ride refinancing shocks successfully, choosing to liquidate assets excessively such that the government has to bailout banks that would have been covered by other banks having a network existed instead.

Our main goal was to highlight the potentially large unforeseen effects of liquidity requirements on network formation and systemic risks. Even though we have focused on liquidity requirements, as banks form networks to face liquidity needs to refinance and continue operations, similar results can be obtained when considering capital requirements and other forms of leverage constraints, as long 790 as those restrictions reduce investments to a level that discourage the formation of networks and the related cross-insurance gains they provide.

The model we have introduced captures the intricate strategic considerations that banks and financial institutions face when choosing counterparties. Its tractability opens the doors to study other interesting questions, which we leave for future research. First, in the model we abstract from potentially interesting trade-offs between liquid and illiquid assets, and then banks choose to invest as much as possible. Having an interior solution for liquid assets as a fraction of illiquid assets would allow, for example, to study how networks evolve in periods of scarce liquidity or high return of illiquid assets.

800 Similarly, introducing aggregate refinancing shocks, or correlation among banks' assets (coming for example from securitization), would also affect how the network structure evolves. We conjecture that, in the same way that there is a level of regulation beyond which a network collapses, there may be also a level of securitization that leads to similar fragility results.

Finally, we have assumed that the government bailout depositors in case of distress, but we leave open the question of what happens when instead a government bailouts banks directly. Indeed, Erol (2016) considers capital injections into banks and shows that the network structure is completely dissolved under such bailouts, and calls this result "network hazard." It is an open question how

network hazard interacts with regulation. 


\section{References}

Acemoglu, D., Ozdaglar, A., Tahbaz-Salehi, A., 2015. Systemic risk and stability in financial networks. The American Economic Review 105, 564-608.

Aldasoro, I., Delli Gatti, D., Faia, E., 2015. Bank networks: Contagion, systemic risk and prudential policy. Working Paper, Goethe University Frankfurt.

Allen, F., 2014. How Should Bank Liquidity be Regulated? Speech at Federal Reserve Bank of Atlanta .

Allen, F., Gale, D., 2000. Financial contagion. Journal of Political Economy $108,1-33$.

Battiston, S., Delli Gatti, D., Gallegati, M., Greenwald, B., Stiglitz, J., 2012. aisons dangereuses: Increasing connectivity, risk sharing, and systemic risk. Journal of Economic Dynamics and Control 36, 1121-1141.

Calomiris, C.W., Heider, F., Hoerova, M., 2014. A theory of bank liquidity requirements. Columbia Business School Research Paper .

825 Cooper, R., Ross, T.W., 1998. Bank runs: Liquidity costs and investment distortions. Journal of monetary Economics 41, 27-38.

Diamond, D., Kashyap, A., 2016. Liquidity requirements, liquidity choice and financial stability. NBER Working Paper 22053.

Diamond, D.W., Dybvig, P.H., 1983. Bank runs, deposit insurance, and liquidity. Journal of Political Economy 91, 401-19.

Ennis, H.M., Keister, T., 2006. Bank runs and investment decisions revisited. Journal of monetary Economics 53, 217-232.

Erol, S., 2016. Network hazard and bailouts. working paper .

Erol, S., Vohra, R., 2016. Network formation and systemic risk. Working Paper, 835 University of Pennsylvania.

Farboodi, M., 2015. Intermediation and voluntary exposure to counterparty risk. working paper .

Farhi, E., Golosov, M., Tsyvinski, A., 2009. A theory of liquidity and regulation of financial intermediation. The Review of Economic Studies 76, 973-992.

Goodfriend, M., 2016. Liquidity regulation, bank capital, and monetary policy. Testimony before the Committee on Banking, Housing, and Urban Affairs U.S. Senate .

van den Heuvel, S., 2016. The welfare effects of bank liquidity and capital requirements. Working Paper, ECB. 
845 Holmström, B., Tirole, J., 1998. Private and public supply of liquidity. Journal of Political Economy 106, 1-40.

Nosal, J., Ordonez, G., 2016. Uncertainty as commitment. Journal of Monetary Economics 80, 124-140.

Ordonez, G., 2016. Sustainable shadow banking. Working Paper, University of 850 Pennsylvania.

Paddrik, M., Park, H., Wang, J.J., 2016. Bank networks and systemic risk: Evidence from the national banking acts. Working Paper, Arizona State University.

Santos, J., Suarez, J., 2015. Liquidity standards and the value of an informed 855 lender of last resort . 


\section{Appendix A. Formal Analysis of the Phase Transition (for online publication).}

Define $\mathcal{B}(\phi)=B L(\phi)-\alpha \kappa_{l}^{\prime}$ and $\varepsilon(d \mid \phi)=(1-\alpha) \operatorname{Pr}_{G}(R(d \mid \phi), d-1,1-\alpha)$. By rearranging terms,

$$
\begin{gathered}
V(d \mid \phi)=\mathcal{B}(\phi) \times\left(d+\frac{A L(\phi)}{\mathcal{B}(\phi)}\right) \times\left(G(R(d \mid \phi), d, 1-\alpha)-\frac{\kappa_{l}}{\mathcal{B}(\phi)}\right) \\
+\frac{A L(\phi) \kappa_{l}}{\mathcal{B}(\phi)}+d B L(\phi) \varepsilon(d \mid \phi)
\end{gathered}
$$

The term with $\varepsilon(d \mid \phi)$ is negligible compared to the other terms. $\frac{A L(\phi) \kappa_{l}}{\mathcal{B}(\phi)}$ is constant with respect to $d$. As $\phi$ increases, $\mathcal{B}$ transits from positive to negative at the threshold $\tilde{\phi}=\frac{B D}{\alpha \kappa_{l}^{\prime}}$. Around this threshold, the optimal $d$ potentially changes dramatically.

The first problem with a formal proof of the characterization of $d^{*}(\phi)$ is that it is not obvious if (and how) the change happens as the signs of $A, k-1-\frac{A L(\phi)}{\mathcal{B}(\phi)}$ and $1-\frac{\kappa_{l}}{\mathcal{B}(\phi)}$ all matter for the full characterization of the solution.

The second problem comes from the discrete structure, which gives rise to the term $\varepsilon(d \mid \phi)$. Under appropriate assumptions $d^{*}$ can be characterized using the Chernoff Bounds on tails of the binomial CDF, however, the term with $\varepsilon(d \mid \phi)$ makes a clean proof cumbersome. Without using Chernoff Bounds, or alike, the discreteness in $R$ also makes analyzing $G$ cumbersome. As $d$ changes, $G$ typically evolves monotonically except at the points that $R$ changes with $d$.

The third problem is about the constant term that contains $A$. When $A \neq 0$, the expression for $R(d \mid \phi)$ does not linearly scale with $d$, making the use of Chernoff bounds intractable.

We manage to overcome the first two problems when $A=0$. Simulations verify the intuition concerning phase transition extends to $A \neq 0$ as well. Moreover, notice that $A=0$ is the boundary between isolated banks continuing or not continuing so the result encompasses both cases.

The resilience of a bank can be written as

$$
\begin{aligned}
R(d \mid \phi)= & -1-S(d \mid \phi)=d-\left\lceil\left(F^{-1}(T(d \mid \phi))-D-W\right) / W\right\rceil \\
= & d-\frac{F^{-1}(T(d \mid \phi))-D-W}{W}-\epsilon_{1}(d \mid \phi) \\
= & d-d \frac{P \alpha \kappa_{l}^{\prime}}{W \alpha \beta L(\phi)}-\frac{P T_{0}-S-W}{W}-\epsilon_{1}(d \mid \phi) \\
=d & \left(1-\alpha+\mathcal{B}(\phi) \frac{P}{W \alpha \beta L(\phi)}\right)+\frac{A P}{\alpha \beta W}-\epsilon_{1}(d \mid \phi) \\
= & d\left(1-\alpha+\mathcal{B}(\phi) \frac{P}{W \alpha \beta L(\phi)}\right)+\epsilon_{1}(d \mid \phi)
\end{aligned}
$$

where $\epsilon_{1}(d \mid \phi) \in[0,1)$ is a ceiling term that guarantees that $R(d \mid \phi)$ is an integer. 
Proposition 2. Suppose that $A=0 . d^{*}(\phi)=0$ for all $\phi>\frac{B D}{\kappa^{*}}$ where

$$
\kappa^{*}=\max \left\{\kappa_{l}, \alpha^{2} \kappa_{l}^{\prime}, \min \left\{\frac{\kappa_{l}}{1-\alpha}, \alpha \kappa_{l}^{\prime}\right\}\right\} .
$$

Proof. The condition is equivalent to $\kappa^{*}>B L$ (we can ignore $\bar{L}$ since it is 880 suffiently large). If $B L<\alpha^{2} \kappa_{l}$ then $R<0$ which implies that the terms with $G$ in $V$ are equal to 1 . Then $V=d\left(\mathcal{B}-\kappa_{l}\right) \leq 0$ for all $d$. Hence $V$ is maximized at 0 . If $B L<\kappa_{l}$, then $V \leq d\left(\kappa_{l}+B L\right) \leq 0$ for all $d$. So $V$ is maximized at $d=0$. If $B L<\frac{\kappa_{l}}{1-\alpha}$ and $B L<\alpha \kappa_{l}^{\prime}$, then $V \leq d\left(-\kappa_{l}+\mathcal{B} G(R(d), d, 1-\alpha)+B L \varepsilon(d \mid \phi)\right) \leq$ $d\left(-\kappa_{l}+B L(1-\alpha)\right) \leq 0$ for all $d$. Thus again, $V$ is maximized at $d=0$.

Proposition 3. Suppose that $A=0 . d^{*}(\phi)=k-1$ for all $\phi<\frac{B D}{\kappa^{* *}}$ where

$$
\begin{gathered}
\kappa^{* *}=\max \left\{\frac{\alpha \kappa_{l}^{\prime}}{1-\frac{\alpha}{1-\alpha}\left(\frac{\varepsilon^{\prime}+\sqrt{\varepsilon^{\prime 2}+8 \varepsilon^{\prime}}}{2}\right)},\right. \\
\left.\frac{\alpha \kappa_{l}^{\prime}+\kappa_{l}}{1-(k-1) \operatorname{Exp}\left[-(1-\alpha)(k-2) \varepsilon^{\prime}\right]},(1.15) \alpha \kappa_{l}^{\prime}+\kappa_{l}\right\}
\end{gathered}
$$

for some arbitrarily chosen $\varepsilon^{\prime}>0$.

Proof. $V=d\left(\kappa_{l}-\alpha \kappa_{l}^{\prime} G(R, d, 1-\alpha)+B L G(R, d-1,1-\alpha)\right) \leq d\left(\mathcal{B}-\kappa_{l}+\right.$ $\left.\alpha \kappa_{l}^{\prime} \zeta\right)$ where $\zeta=1-G(R, d, 1-\alpha)$. The Chernoff bounds imply that $\zeta \leq \chi=$ $\operatorname{Exp}\left(-\frac{\delta_{L}^{2}}{2+\delta_{L}} \mu_{d}\right)$ where $\mu_{d}=d(1-\alpha)$ and $\delta_{L}$ is given by $\left(1+\delta_{L}\right) \mu_{d}=R$ (i.e. $\left.\delta_{L}=\frac{\alpha}{1-\alpha}\left(1-\frac{\alpha \kappa_{l}^{\prime}}{B L}\right)\right) 1516$

${ }_{890}$ We first show that if $\frac{\mathcal{B}-\kappa_{l}}{\alpha \kappa_{l}^{\prime}}>0.15$, then the upper bound for $V, d(\mathcal{B}-$ $\left.\kappa_{l}+\alpha \kappa_{l}^{\prime} \chi\right)$, is increasing in $d$. The derivative of the continuum version of the upper bound in $d$ is $\mathcal{B}-\kappa_{l}+\alpha \kappa_{l}^{\prime} \chi(1-m)$, where $m=d \frac{\delta_{L}^{2}(1-\alpha)}{2+\delta_{L}}$. Notice that $\chi=\operatorname{Exp}(-m)$. Also note that $\frac{m^{\prime}-1}{\operatorname{Exp}\left(m^{\prime}\right)}<0.15$ for any value of $m^{\prime}>0$. Hence $\frac{\mathcal{B}-\kappa_{l}}{\alpha \kappa_{l}^{\prime}}>0.15>(m-1) \chi$ meaning that the derivative is positive.

Then for any $d \leq k-2 . V(d) \leq d\left(\mathcal{B}-\kappa_{l}+\alpha \kappa_{l}^{\prime} \chi_{d}\right) \leq(k-2)\left(\mathcal{B}-\kappa_{l}+\alpha \kappa_{l}^{\prime} \chi_{k-2}\right)$ Now we find an appropriate lower bound for $V(k-1)$ and show that $V(d)<$ $V(k-1)$ for any $d \leq k-2$. Since $\varepsilon(d \mid \phi \geq 0), V(k-1) \geq(k-1)\left(\kappa_{l}+\mathcal{B}-\mathcal{B} \chi_{k-1}\right)$. That means we need to prove $\alpha \kappa_{l}^{\prime}(k-2) \chi_{k-2}+\mathcal{B}(k-1) \chi_{k-1} \leq \mathcal{B}-\kappa_{l} . \chi_{d}$ is decreasing since $R_{d}>\mu_{d}$. Thus, a sufficient condition is $(k-1) \chi_{k-2}\left(\mathcal{B}+\alpha \kappa_{l}^{\prime}\right) \leq$ $\mathcal{B}-\kappa_{l}$. Now we prove that if $\phi<\frac{B D}{\kappa^{* *}}$, the condition holds.

The sufficient condition is equivalent to

$$
\frac{\alpha \kappa_{l}^{\prime}+\kappa_{l}}{B L}+(k-1) \operatorname{Exp}\left(-(1-\alpha)(k-2) \frac{\delta_{L}^{2}}{2+\delta_{L}}\right) \leq 1 .
$$

\footnotetext{
${ }^{15}$ Here $A=0$ plays a key role. Otherwise, $\delta$ would depend on $d$ and it would make the analysis more complicated.

${ }^{16}$ Here we have ignored the term $\epsilon_{1} \in[0,1)$ which makes no difference to the analysis but it is very costly in notation to explore.
} 
Both of the summands are in increasing in $L$. Then if $\frac{\delta_{L}^{2}}{2+\delta_{L}}$ is less than $\varepsilon^{\prime}$ and also

$$
\frac{\alpha \kappa_{l}^{\prime}+\kappa_{l}}{B L}+(k-1) \operatorname{Exp}\left(-(1-\alpha)(k-2) \varepsilon^{\prime}\right) \leq 1,
$$

the sufficient condition holds. The first bound on $\phi$ imples the first (by solving the quadratic), and the second bound on $\phi$ implies the second. (The third bound on $\phi$ corresponds to the condition guaranteeing that the upper bound on $V(d)$ is increasing.) 